\title{
LinkedIn: do grêmio estudantil ao mercado de trabalho.
}

LinkedIn: from the student government to the job market.

Raudiner Railton dos Santos, mestrando, Universidade Estadual de Campinas (UNICAMP), raudiner@gmail.com

\section{Resumo}

Inspirado em um documentário sobre educação e considerando teorias acerca de gênero do discurso e letramentos, este artigo tem como objetivo principal apresentar uma proposta didática na qual seja proposta a eleição de um grêmio estudantil em que o currículo online seja requisitado aos alunos e trabalhado com eles.

Palavras Chave: Tecnologias Digitais de Informação e Comunicação (TDICs); Gênero; Letramentos.

\begin{abstract}
Inspired by an educational documentary and considering theories about speech genres and literacies, this articles aims to introduce a didactic proposal in which the election for the student government is proposed, wherein the online curriculum is requested to the students and worked with them.
\end{abstract}

Keywords: Information and Communication Digital Technologies (ICDTs); Genre; Literacies. 


\section{Introdução}

É dever da escola a missão de educar, seja para a vida escolar, seja para mundo. Para que isto seja efetivo, devemos considerar as diversas esferas de comunicação humana que exigem os diversos tipos de letramentos.

Quando pensamos nessa educação, não devemos ignorar as cartilhas governamentais ou os materiais didáticos adotados pela escola. Contudo, torna-se ingênuo acharmos que todas as respostas para o preparo efetivo de um cidadão letrado - em diversos quesitos - e alfabetizado se encontram nesses documentos.

Para tanto, torna-se necessária a preparação do professor para que este entenda o mundo além da rede escolar e as demandas deste mundo para, assim, ter uma melhor avaliação de sua prática docente a fim de transmitir, ensinar e preparar o seu aluno para o reconhecimento e participação efetiva da/na gama das demandas sociais.

Neste sentido, não podemos isolar o papel das Tecnologias Digitais de Informação e Comunicação - doravante TDICs - da vida em sociedade, uma vez que, por estarem presentes não somente no cotidiano dessa nova geração de alunos, mas também em diversas esferas de comunicação humana, obrigam-nos a inserirmos no ensino - de todas as áreas - o manuseio e a aplicabilidade desta nova ferramenta.

\section{Problema}

Sabe-se que hoje a escola é a instituição formal para a preparação de um indivíduo em cidadão. Para isto, o aluno, desde muito cedo, começa por aprender as regras de sua própria língua e os cálculos mais básicos de matemática. Ao longo dos anos, é inserido em sua rotina História, Geografia e Ciências, para, mais tarde, ter acesso a línguas estrangeiras e ver Ciências se desmembrar em Biologia, Física e Química, já no Ensino Médio. Tudo isso dividido em uma média de cerca de vinte a trinta aulas por semana, inseridas em um período letivo, no qual o aluno se encontra sentado o tempo todo em uma carteira com o livro e o caderno abertos virado para a lousa de giz branco.

No entanto, esta divisão de matérias e conteúdos, que por anos gera debate entre educadores e governantes em relação à forma e (re) construção do currículo, possui algo muito característico: a tradição do ensino. Ao entendermos a definição de "tradição", neste caso, não pensamos como algo espetacular que é transmitido às pessoas por uma forma (quase) sem falhas. Entendemos, contudo, o atraso que a escola está submetida por, ainda, manter antigas práticas de letramentos - que, muitas vezes, não condizem com o atual contexto social ou que já são consideradas incipientes - e não abrir espaço para o novo; o diferente; o revolucionário.

Há diversas razões que estimulam este debate para a revolução da educação, assim como há também diversos argumentos contrários que privilegiam a 
continuidade das práticas de ensino da maneira pela qual conhecemos. Diversas vezes, observamos que estes argumentos ganham mais consistência na "efetividade" de manter as práticas da maneira que estão ao evidenciarmos que há políticas públicas que impedem as mudanças tão desejadas, da mesma forma que também encontramos despreparo na formação do corpo docente para aceitação e utilização de uma nova forma de ensino. Ao relativizarmos essa questão para o papel da tecnologia na educação, temos, como problemas, a falta de investimento dos governos em materiais digitais de diversas ordens - sejam estes materiais os tablets, por exemplo, assim como a lousa digital, caixas de som, data show, etc. -, uma vez que, ao inserirmos tais mudanças nas salas de aulas, as editoras de livros didáticos teriam um grande rombo em suas finanças, já que os governos não precisariam manter contratos anuais para a impressão de materiais didáticos. Além disso, há falta de investimento em capacitação docente desde a Graduação, uma vez que há uma carência de profissionais que entendem e sabem aplicar a tecnologia para este meio, assim como se tem uma grande influência dos vestibulares na construção de edições didáticas, já que muitos sistemas de ensino vendem seus serviços como um passaporte de ingresso na universidade e, para isso, ignoram a formação cidadã e os requisitos exigidos pela sociedade. Dessa forma, formam-se educadores analfabetos digitais que continuam com suas aulas inteiramente expositivas, nas quais é mandatório o segmento do livro didático.

Por isso, cabe a nós - professores/educadores e pesquisadores - procurarmos maneiras que validem, ainda que de forma crua, o uso das TDICs em sala de aula, já que, nenhum sistema de ensino é inteiramente fechado a ponto de não encontrarmos brechas que permitam reinventarmos práticas docentes.

\section{Propósito}

Haja vista os empecilhos descritos, temos como propósito apresentarmos uma maneira que ateste os usos das TDICs como uma forma de trabalhar novos letramentos na escola.

Para tanto, almejamos que nosso aluno seja capaz de perceber que dentro de estruturas rígidas e tradicionais - tais como a escola, por exemplo - há espaço para mudanças nas práticas sociais. Mais ainda, queremos mostrar que algumas destas práticas, embora não aconteçam no ambiente escolar, já são efetivas na sociedade, como, por exemplo, a elaboração de um currículo digital.

Por isso, nossa maior aspiração é trazermos um contexto real de uso da tecnologia no ensino de Língua Portuguesa tendo em vista as reais demandas externas. Em outras palavras, queremos promover o debate das exigências do mercado de trabalho para que possamos fazer uso de uma ferramenta (LinkedIn) para a construção de um currículo digital, utilizando os diversos recursos que a plataforma oferece a fim de ganhar destaque perante outros concorrentes na disputa por uma vaga. Para isto, devido à faixa etária (14 anos), traremos o uso da 
ferramenta para o preenchimento das vagas da eleição do grêmio estudantil, na qual os alunos terão a oportunidade de se candidatar a elas por meio de seus currículos. Ao mesmo tempo, alunos votantes, docentes e funcionários terão acesso ao perfil/currículo dos alunos candidatos a fim de indicá-los e os elegerem para a gestão.

\section{Abordagens Teóricas}

Embora tenhamos discursado sobre uma revolução da educação, há, ainda, raízes em nossas práticas que nos impedem de extinguirmos toda e qualquer atitude perante o que julgamos velho, ultrapassado.

Neste sentido, conforme mencionado anteriormente, procuramos uma brecha na utilização dos currículos e materiais didáticos impostos pelos governos e/ou sistemas de ensino para elaborarmos novos planos de aula que façam uso das TDICs, mas que, ainda, condizem com o planejamento proposto pelas instituições de ensino.

Desta forma, ao escolhermos o gênero currículo para ser trabalhado nesta proposta didática, não dispensamos as contribuições feitas por Bakhtin (2003[19521953/1979]) acerca da teoria de gênero. O autor elaborou estudos a respeito, principalmente, da definição de gênero de discurso (como pertencente a esferas de atividade), dos componentes dos gêneros (forma composicional, estilo e tema), da divisão de gêneros (em primários e secundários), para esclarecer o funcionamento do enunciado. Desta maneira, Bakhtin (2003 [1952-1953/1979]) faz algumas considerações importantes, tais como:

- O caráter e os modos de uso da língua são variáveis, assim como as esferas de atividade humana;

- O uso da língua é feito através de enunciados, os quais possuem três elementos: conteúdo temático, estilo verbal e a construção composicional;

- O enunciado permite refletir as condições específicas e as finalidades das esferas de atividade humana e cada uma dessas cria seus tipos de enunciado, o que é denominado gênero do discurso. A variedade desses gêneros é infinita;

- Por fim, quanto mais complexa fica a esfera, mais complexo se torna o gênero.

Ao trazermos essa teoria para o nosso campo de aplicabilidade, torna-se essencial trabalhamos com nossos alunos esta questão de esfera, uma vez que, ao introduzirmos um contexto que seja uma reprodução de uma competição no "mercado", devemos transmitir a obrigação da formalidade exigida pela esfera e os requisitos necessários para a criação de um currículo que seja destaque perante aos 
outros. Para isso, faz-se preciso também apresentar maneiras de evidenciar características e habilidades que sejam condizentes com o cargo pretendido.

Contudo, embora pareça uma prática simples, devemos considerar que nossos alunos ainda não possuem as competências e habilidades necessárias para esta prática de letramento: feitura/preenchimento de currículo. Por isso, recorremos também a teoria de letramento(s), utilizando Street (2003) e Soares (1998).

Acerca disto, é interessante que considerarmos a perspectiva de Street (2003) quando o autor mostra que os novos estudos do letramento representam uma nova abordagem que não tem como foco somente a aquisição dos letramentos valorizados - aqueles privilegiados pela mídia e pela escola -, mas sim, os letramentos que têm impacto nas causas sociais - dominantes ou vernaculares. Assim, primeiramente, é preciso que se reconheça o termo letramentos, já que são múltiplos e variam, certamente, de acordo com o tempo, o espaço e as culturas, mas também que confrontam as relações de poder nas sociedades.

Para Street (2003), letramento é um termo usado para resumir as práticas sociais e as diversas concepções que as embasam de leitura e escrita, fazendo com que o termo ganhe um significado político e ideológico, os quais não podem ser separados e nem tratados como fenômenos autônomos.

Portanto, Soares (1998) acredita que os conceitos de letramento(s) são fundamentados na sua necessidade para o efetivo funcionamento na sociedade ou na sua potencialização para a transformação das relações públicas e sociais injustas.

Em caráter de complementação, não podemos ignorar Kleiman (1995) nesta discussão, uma vez que a autora nos direciona para entendermos os propósitos dos diferentes tipos de letramentos e a espinha dorsal escolar. Ou seja, para a autora, é evidente que a concepção de letramentos ultrapassa o universo da escrita regido pelas instituições escolares, uma vez que a escola preocupa-se com a aquisição de "conhecimento" que será utilizado para que se tenha um bom êxito dentro dela mesma (alfabetismos, capacidades, estratégias). Em outras palavras, é ignorada a construção dos conhecimentos para o bom êxito também nas práticas sociais.

O modelo autônomo do letramento, frequentemente adotado pela escola, "pressupõe que há apenas uma maneira de o letramento ser desenvolvido, sendo que esta forma está associada quase que causalmente com o progresso, a civilização, a mobilidade social" (KLEIMAN, 1995, p. 21).

Em contrapartida, há o modelo ideológico de letramento, que pressupõe uma dimensão social para a escrita e não permite qualquer relação entre letramento e modernização, quebrando assim, os limites entre o oral e o escrito. Assim, por estar sempre apoiado num contexto social, o letramento acaba mesmo por ganhar um propósito e, diferentemente do outro modelo, não está preso somente a um círculo individual.

Como estamos trabalhando com a transposição de um currículo impresso para uma mídia digital, utilizamos a visão de Rojo (2009), na qual a autora expõe a 
necessidade do trabalho com os letramentos multissemióticos, já que se faz preciso introduzi-los na leitura e na produção de textos em diversas linguagens e semioses, sendo que essas múltiplas linguagens, juntamente com as capacidades de leitura e produção por elas exigidas, são constitutivas dos textos contemporâneos. Ainda na visão da autora, é indispensável o trabalho com os letramentos críticos, ou seja, abordar os diversos tipos de textos das diversas mídias e culturas, levando em consideração a discursividade, o contexto histórico, a ideologia, os efeitos de sentido e tudo mais que possa os envolver, para que os alunos sejam capazes de criticá-los e desvelar as suas finalidades.

Por fim, como a plataforma oferece a oportunidade de fazer indicações e comentários a respeito do dono do currículo, o conceito de novos letramentos, trazido por KNOBEL \& LANKSHEAR (2007) e explorado por Pinheiros (2014) também se faz necessário, uma vez que o fato de a ferramenta permitir interatividade entre os usuários dá a eles a oportunidade de participar ativamente/diretamente na construção do significado, uma vez que o comentário do outro a meu respeito influencia diretamente na visão que um terceiro tem sobre mim, o que causa uma desestabilização da noção de autoria e acarreta em um produto cooperativo. Temse, neste caso, um novo ethos na web 2.0, ou seja, novas práticas de leitura e escrita.

\section{Métodos}

Inspirados e baseados em diversas discussões trazidas pelos autores presentes na obra "Psicologia da Educação Virtual: aprender e ensinar com as Tecnologias da Informação e da Comunicação" organizada por COLL \& MONERO (2010), o trabalho se dará pelas seguintes etapas:

1. Os alunos assistirão ao documentário "Quando sinto que já sei" (www.quandosintoquejasei.com.br) para terem contato com diversas formas de educação, porém, com atenção especial para o projeto de "República das Crianças" promovido pela escola EMEF Campos Salles, em São Paulo. Neste projeto, que visa a autonomia, responsabilidade e solidariedade, os alunos, através dos auxílios dos docentes, possuem cargos definidos por votação pela comunidade escolar, tendo, como foco, o desenvolvimento democrático;

2. O educador apresentará os cargos disponíveis no grêmio estudantil e fará um debate acerca das habilidades necessárias para preenchê-los;

3. O educador promoverá outro debate sobre o mercado de trabalho e como a apresentação das nossas habilidades influencia na escolha de nossos empregadores. A partir disso, o professor trabalhará o gênero currículo impresso, conforme prevê o Parâmetro Nacional de Ensino Fundamental 


\section{V SILID IV SIMAR \\ PUC-Rio - Dias 28, 29 e 30 de julho de 2015}

(PCNEF) para, então, trabalhar as diferenças promovidas no currículo digital (LinkedIn).

4. Os alunos preencherão seus currículos na plataforma digital de modo a evidenciar suas habilidades e sua trajetória escolar e extraescolar de acordo com a vaga pretendida.

5. Eles conversarão com docentes e funcionários da escola para que estes escrevam referências nos currículos de modo a evidenciá-los.

6. Toda a comunidade escolar lerá os currículos e as indicações feitas aos concorrentes e votará no que julgue mais preparado para o cargo.

\section{Considerações}

Como se trata de um projeto-piloto, não temos resultados para provarmos de quão positivo é o uso da TDICs neste caso. No entanto, considerando a linha teórica traçada e os problemas enfrentados pela educação brasileira, acreditamos que é uma maneira, ainda que singela, de promover um debate de toda a comunidade acadêmica das escolas do Brasil e deixar mais real e mais palpável um dos inúmeros conteúdos trabalhados em Língua Portuguesa. Por isso, vemos neste exemplo o quanto o uso das tecnologias torna este objetivo mais significativo.

\section{Referências Bibliográficas}

BAKHTIN, M. "Os gêneros do discurso". In: Estética da criação verbal. São Paulo: Martins Fontes, 1992.

COLL, C. MONEREO, C. Psicologia da educação virtual: aprender e ensinar com as tecnologias da informação e da comunicação. Porto Alegre: Artmed, 2010.

KLEIMAN, A. B. "Modelos de letramento e as práticas de alfabetização na escola". In: Os significados dos letramentos: Uma nova perspectiva sobre a prática social da escrita. Campinas, SP: Mercado de Letras, 1995.

KNOBEL, M.; LANKSHEAR, C. A new literacies sampler. New York: Peter Lang Publishing, Inc., 2007.

PINHEIRO, P. A. A ERA DO "MULTISSINÓPTICO": QUE (NOVOS) LETRAMENTOS ESTÃO EM JOGO? Educação em Revista, n.02, p.137-160, Abril-Junho 2014. 
ROJO, R. Letramentos múltiplos, escola e inclusão social. São Paulo: Parábola Editorial, 2009.

SOARES, M. "O que é letramento?", "O que é letramento e alfabetização", "Letramento: como definir, como avaliar, como medir". In:

Letramento: um tema em três gêneros. Belo Horizonte: Editora Autência. 2a edição, 1998.

STREET, B. "What's 'new' in New Literacy Studies? Critical approaches to literacy in theory and practice". In: Current issues in Comparative Education. London: Kings College, 2003. 